\title{
Design of a High Sea Wave Sensor System in Puger Beach
}

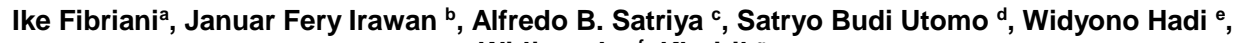
Widjonarko ${ }^{f}$, Khoiril ${ }^{g}$

a,b,c,d,e,f,gUniversity of Jember, Indonesia

e-mail:ik3fibriani.teknik@gmail.com, januar ir@yahoo.com, alfredobayusatriya@gmail.com, satryo@unej.ac.id, widyono.hadi1961@gmail.com, widjonarko.teknik@unej.ac.id

\begin{abstract}
Indonesia is an archipelagic country that has a very wide sea area. Thus, Indonesian sea has a huge potential of natural resources that can be utilized to grow the nation's economy. There are many occupations and efforts that can be done to increase the income from the sea and also to conserve it. Fishery is one of the most effective way to gain the sea resources; however, fishery is limited by the weather condition on the sea. This is also a problem that happened in Puger Beach. Puger Beach is located in the south Jember and it faces the Hindia Ocean, which means the weather condition is more dangerous for fishermen than other part of coastal. To ensure the safety of the fishermen, the weather condition on the sea must be evaluated and predicted before the fishery. This study aims to design a system to provide fishermen in Puger Beach an information about sea and beach weather condition which consist of wave height prediction, wind speed, temperature, humidity and weather prediction. The wind speed is obtained from self-designed anemometer system, the temperature is measured using LM35 sensor, and the humidity is assessed using DHT22. The wave height in the sea was predicted by calculating the wind speed value and effective average fetch value using neural network algorithm. The weather on the sea and on the beach were predicted by rain and light sensor. This weather prediction would be classified into three different results, namely raining, cloudy and bright. After some experiments, the result showed that the device can provide the information needed for fishermen and it has a high sensing accuracy. The humidity measurement had an average error of $1.1 \%$, the temperature measurement had $1.42 \%$ average error, and $2.37 \%$ for the wind speed measurement. The wave height measurement system worked out and found the average wave height in Puger Beach 0.37 meters.
\end{abstract}

\section{INTRODUCTION}

The increasing weather variability, intensity of cyclone, and sea wave due to global warming occurred in many parts of the world. In Indonesia, cyclone and high sea wave usually occur in the transition between rainy and dry season. Both cyclone and high sea wave impact community welfare in the form of damages and losses. Since there is still no technology to stop the occurrence of both cyclone and high sea wave, the effort to minimize the damages and losses can be mitigated through community preparedness, timely warning, and effective response [1]. Hence, an effective warning system for cyclone and high sea wave need to be designed to increase disaster resilience of community.

Community with high disaster resilience can adapt successfully to disaster and adopt strategies which include means for further increasing their disaster resilience, one of which is disaster warning system [2]. Disaster warning system can be effective or ineffective, or somewhere between these two extreme point. However, an effective one has two main features, first it provides timely meteorological forecasts; second, it gives a welldisseminated warning [3].Currently, information on marine weather conditions in Indonesia has been provided by Indonesian Bureau of Meteorology, Climatology, and Geophysics 
through website. However it is not easily accessible to all and the information provided is not in real time. Based on the previous definition of an effective disaster warning system, the current warning system for cyclone and high sea wave in Indonesia is not effective since it cannot provides timely meteorological forecast and well-disseminated warning. Thus in Indonesia, the need for system that provides accurate and timely information is increasingly high, since such system can help in reducing the potential losses and damages from disaster and increases community disaster resilience.

Hence, the main purpose of this study is to design a system which gives an accurate prediction on weather condition, cyclone and high sea wave utilizing weather sensor. Similar studies have been conducted by [1], [2], [5], [6], [7], [8], [9], and [10], in which they include climate and weather parameters. Another study by Coastal Engineering Research (1984) designed a system providing weather prediction for fisherman, however the accuracy of resulting prediction has not been tested. Specifically, the purpose of this study is to design a warning system utilizing data from weather sensors to predict the occurrence of cyclone and high sea wave and test the accuracy of prediction from the system.

\section{METHOD}

The system consists of three main components, namely (1) Sensors; (2) Arduino Uno; (3) Laptop. The working of the system represented by block diagram which is shown in Figure 1. The methods of design were as follows: defining the objective, identify the components, identify the data sources and indicators, design data processing system, and testing the system. Based on the block diagram, Arduino Uno is used to read both analog and digital data gathered from each sensor. The first sensor, anemometer, utilized to gather data on windspeed and then Arduino Uno converted this data to wave height by finding the value of angle of fetch [2] [3] as shown in Figure 2 (a). Then the next step is to calculate and forecast the windspeed based on data gathered from anemometer using neural network, as shown in Figure 2 (b). The second sensor, DHT22, is utilized to collect temperature and humidity data. The third and fourth sensors, LDR and rain sensor, were utilized to detect weather condition. LDR is utilized to detect clear or cloudy weather, while rain sensor is utilized to detect the existence of rain. All data pertaining to each sensor will be processed by Arduino Uno to get values wich correspond to the actual conditions. Then, the data from Arduino Uno will be transferred to laptop to be further processed using visual studio 2012 and presented as weather information system containing information on windspeed, air temperature and humidity, wave height, and weather condition and suggestion for fisherman safety based on wave height also included, like shown in Figure 3 (a). The forecasting system has a dimension of $41 \mathrm{~cm}$ in length, $19 \mathrm{~cm}$ in width, and 38 $\mathrm{cm}$ in height. The system consists of: (1) Anemometer sensor, (2) Rain sensor, (3) light sensor, (4) DHT22 sensor, (5) Laptop, (6) Arduino Uno. The physical appearance of the system is shown on Figure $3(\mathrm{~b})$.

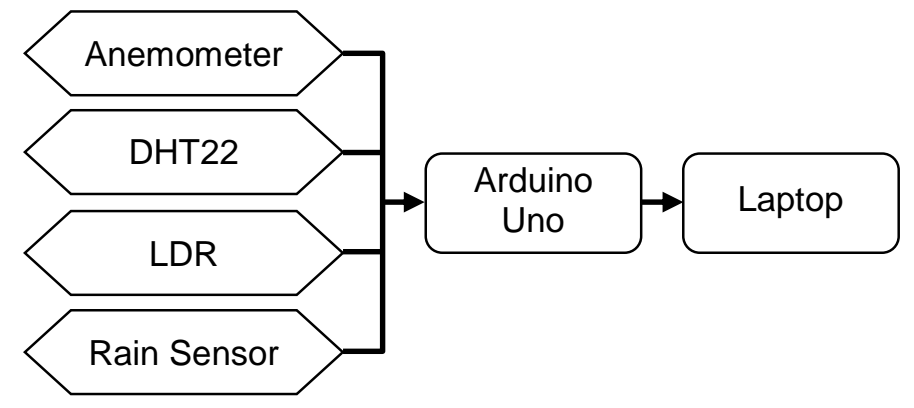

Figure 1. The proposed weather forecasting system 


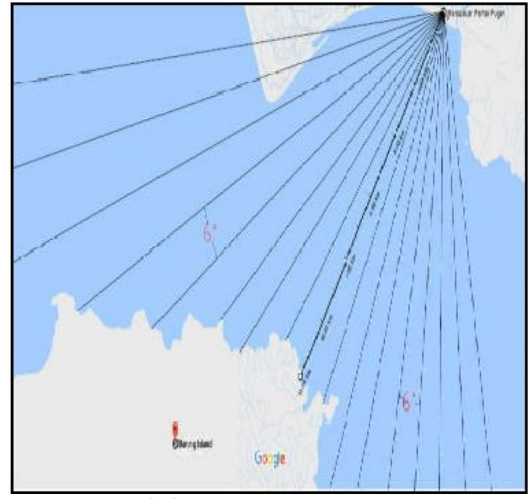

(a)

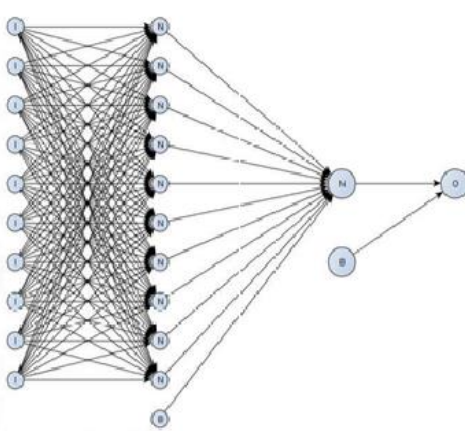

(b)

Figure 2. (a) Determination of fetch angle, (b) Neural network structure of the proposed system

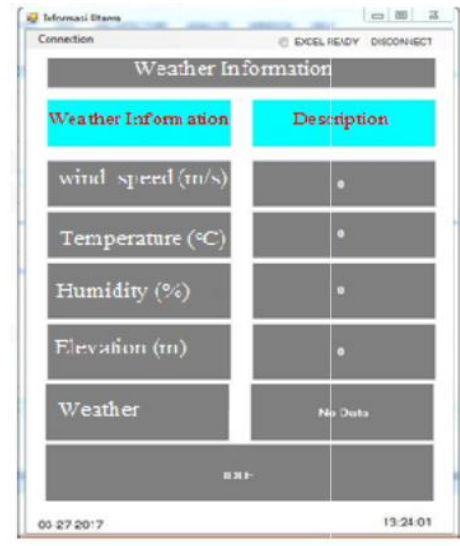

(a)

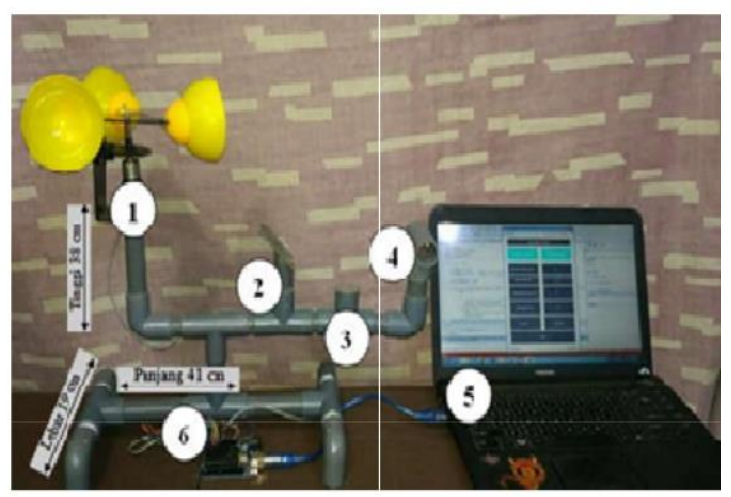

(b)

Figure 3. The designed system; (a) weather information system, (b) the physical appearance

\section{RESULTS AND Discussion}

Tests to determine the accuracy of the system were consisted of (1) testing the accuracy of each sensor separately, and (2) testing the accuracy of the overall system.

\subsection{Anemometer Test}

In this system, the anemometer sensor was constructed using encoder and a series of opto interrupt created using MOC70T3 sensor. Encoder will interrupt the infrared from MOC70T3 sensor, then the sensor will produce pulses to indicate whether the infrared interrupt ted or not. The encoder used in this system is spherical and has 22 holes. The output of opto interrupt in the form of pulses, can be calculated by microcontroller which then be converted into wind speed. The wind speed generated is then compared to the result from calibrated tool to determine its accuracy. Error (\%) was obtained from:

$$
\text { Percent Error }=\frac{(\text { Anemometer reading-Calibrating tool })}{\text { Calibrating tool }}
$$

The test result shown in Table 1.

Table 1. Anemometer test result

\begin{tabular}{lccc}
\hline No & \begin{tabular}{c} 
Calibrating tool \\
\cline { 2 - 3 }$(\mathbf{m} / \mathbf{s})$
\end{tabular} & Anemometer & Error \% \\
\hline 1 & 0 & 0 & 0 \\
2 & 0.5 & 0.53 & 6 \\
3 & 1.6 & 1.6 & 0 \\
\hline
\end{tabular}


JEMMME (Journal of Energy, Mechanical, Material, and Manufacturing Engineering)

Table 1. Anemometer test result (continued)

\begin{tabular}{|c|c|c|c|}
\hline \multirow[b]{2}{*}{ No } & \multirow{2}{*}{$\frac{\text { Calibrating tool }}{(\mathrm{m} / \mathrm{s})}$} & \multirow{2}{*}{$\begin{array}{c}\text { Anemometer } \\
(\mathrm{m} / \mathrm{s})\end{array}$} & \multirow[t]{2}{*}{ Error \% } \\
\hline & & & \\
\hline 4 & 1.7 & 1.75 & 2.9 \\
\hline 5 & 1.8 & 1.79 & 0.5 \\
\hline 6 & 2 & 2.09 & 4.5 \\
\hline 7 & 2.1 & 2.05 & 2.4 \\
\hline 8 & 2.2 & 2.13 & 3.2 \\
\hline 9 & 2.3 & 2.28 & 0.9 \\
\hline 10 & 2.4 & 2.44 & 1.6 \\
\hline 11 & 2.5 & 2.59 & 3.6 \\
\hline \multirow[t]{2}{*}{12} & 3.1 & 3.01 & 2.9 \\
\hline & $\begin{array}{l}\text { Average } \\
\text { Error }\end{array}$ & & 2.375 \\
\hline
\end{tabular}

\subsection{DHT22 Sensor Test}

To test the accuracy of DHT22 sensor in measuring air temperature and humidity, a comparison between the measurement result from DHT22 sensor and the result of manual measurement of air temperature and humidity using thermometer and hygrometer was conducted. The result of the test shown in Figure 4 (a) for temperature and figure 4 (b) for humidity. From both result shown in figure 7 and figure 8 , the average error from temperature test is $1,42 \%$ while the average error from humidity test is $1,1 \%$.

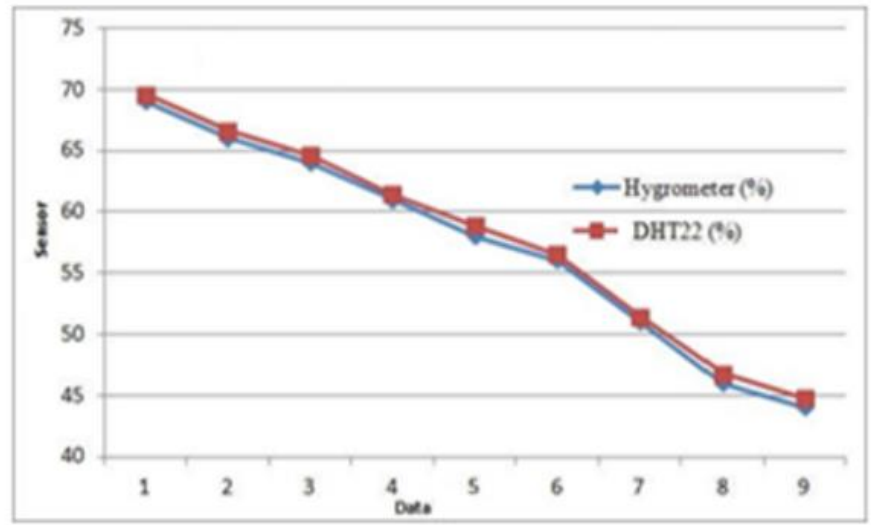

(a)

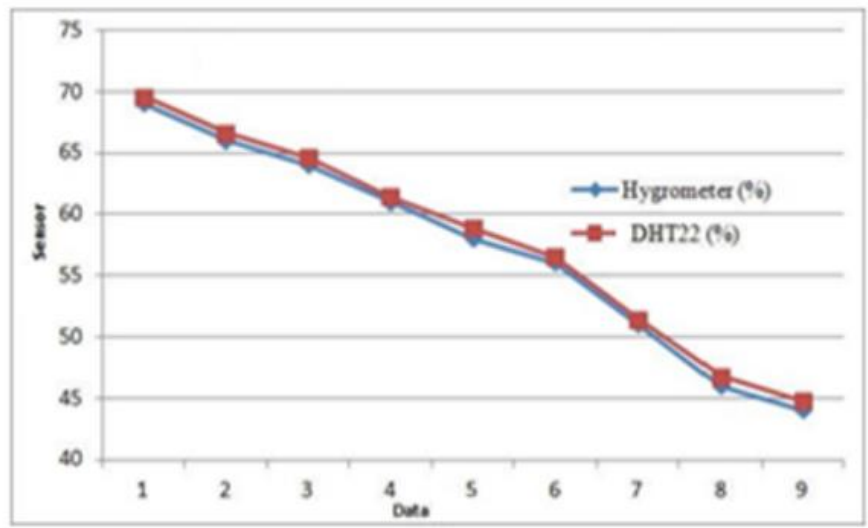

(b)

Figure 4.The result of DHT22 Sensor Test on (a) temperature and (b) humidity 


\subsection{LDR and Rain Test}

To test the accuracy of LDR sensor in predicting clear and cloudy weather, the comparison of the actual weather condition and the reading of the sensor was conducted. LDR sensor will give an ADC value less than 600 when the weather is clear and an ADC value greater than 600 when the weather is cloudy. Based on the test, LDR sensor gives an accurate reading of the actual weather condition. The result of the test shown in Table 2. The same procedure as that on LDR sensor test was used in testing the accuracy of rain sensor. Rain sensor will give an ADC value less than 600 when the actual weather is rainy and an $A D C$ value greater than 600 when it is not.

\begin{tabular}{ccc}
\multicolumn{3}{c}{ Table 2. The ADC value based on $L D R$ and Rain Sensor Test } \\
\hline No & ADC Value & Actual Weather \\
\hline 1 & $<600$ & Clear \\
2 & $\geq 600$ & Cloudy \\
\hline
\end{tabular}

\subsection{Neural Network Test}

Neural network test conducted in three stages, (1) training data, to obtain the best model; (2) validation, to test whether the best model obtained actually good; (3) testing, to evaluate the result of the model. Based on Figure 5 (a), the best mean squared error obtained when epoch value is 462 . To determine the response of output and target $\mathrm{i}$ training, validation and test stages to time, the test like shown in Figure 5 (b) is conducted. To forecast wave height using windspeed through neural network, the actual data gathering was conducted. The data gathering in this study conducted in two days when the sea wind blows starting at 9 a.m. to 4 p.m. local time. The comparison between windspeed and wave height shown in Figure 6.

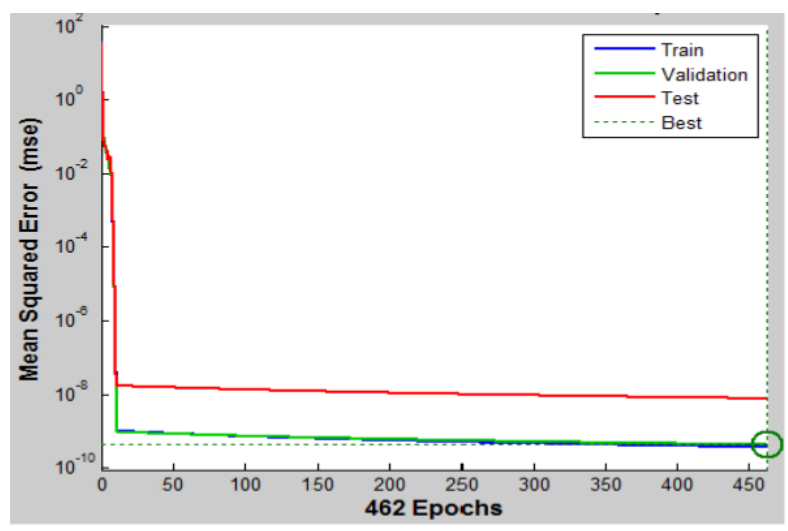

(a)

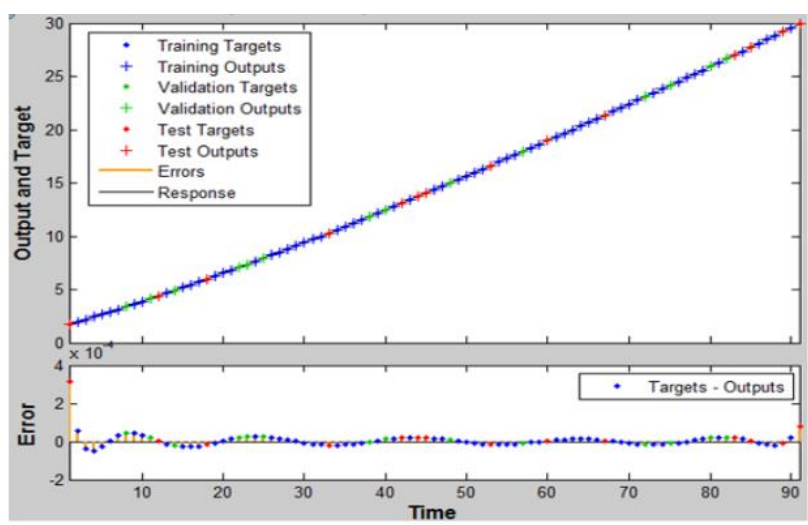

(b)

Figure 5.The result of DHT22 Sensor Test on (a) temperature and (b) humidity 


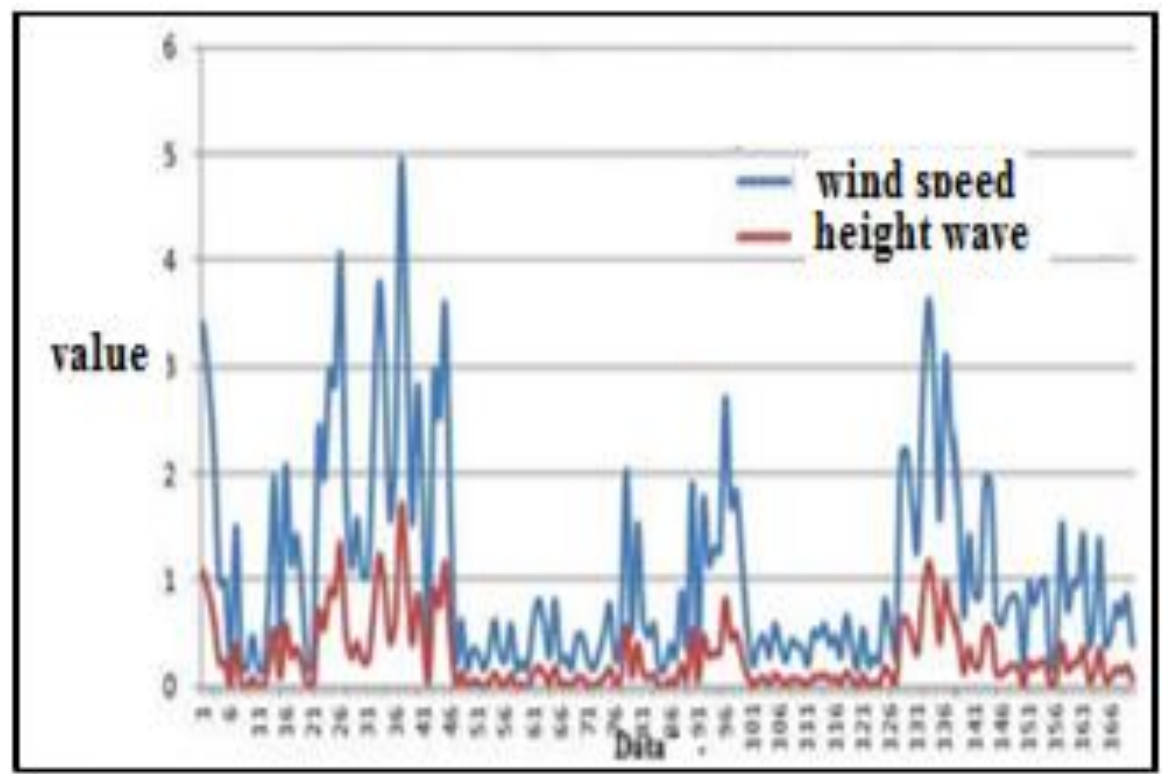

Figure 6. The result of measurement on wind speed and height wave

\subsection{Overall System Test}

The final test of the system was conducted to give information of coast actual weather. The test conducted in 2 days in Puger Coast, 40 meter high. The data gathered when the sea wind blows between 9 a.m. and 4 p.m. local time, the data gathered on 5 minutes interval. The data shown in Table 4 is data gathered on hourly interval.

\begin{tabular}{lccc}
\multicolumn{1}{c}{ Stage } & Samples & MSE & Regression \\
\hline Training & $70 \%$ & $3.66349 \times 10^{-10}$ & $9.99999 \times 10^{-1}$ \\
Validation on & $15 \%$ & $4.27994 \times 10^{-10}$ & $9.99999 \times 10^{-1}$ \\
Testing & $15 \%$ & $7.68634 \times 10^{-9}$ & $9.99999 \times 10^{-1}$ \\
\hline
\end{tabular}

Table 4. Overall System Test Result

\begin{tabular}{cccccccc}
\hline No & Time & $\begin{array}{c}\text { Wind speed Temperature Humidity } \\
(\mathbf{m} / \mathbf{s})\end{array}$ & $\begin{array}{c}\text { Wave } \\
\text { height }(\mathbf{m})\end{array}$ & Weather & Warning \\
\hline 1 & 09.00 & 3.39 & 27.9 & 85.8 & 1.09 & cloudy & safe \\
2 & 10.00 & 0.88 & 26.2 & 92.5 & 0.21 & cloudy & safe \\
3 & 11.00 & 2.82 & 25.3 & 95.1 & 0.87 & cloudy & safe \\
4 & 12.00 & 14.91 & 25.7 & 93.7 & 1.72 & cloudy & beware \\
5 & 13.00 & 0.15 & 25.7 & 92.1 & 0.01 & cloudy & safe \\
6 & 14.00 & 0.57 & 25.6 & 92 & 0.12 & cloudy & safe \\
7 & 15.00 & 0.3 & 25.1 & 92.7 & 0.05 & cloudy & safe \\
8 & 16.00 & 0.15 & 24.7 & 94.6 & 0.01 & cloudy & safe \\
9 & 17.00 & 0.38 & 24.8 & 95.6 & 0.07 & cloudy & safe \\
10 & 18.00 & 1.83 & 24.8 & 94.2 & 0.51 & cloudy & safe \\
11 & 19.00 & 0.34 & 25 & 93 & 0.06 & cloudy & safe \\
12 & 20.00 & 0.19 & 25 & 92.8 & 0.02 & cloudy & safe \\
13 & 21.00 & 2.89 & 25.3 & 90.8 & 0.9 & cloudy & safe \\
14 & 22.00 & 0.57 & 24.8 & 93.2 & 0.12 & cloudy & safe \\
15 & 23.00 & 0.72 & 23.9 & 98.5 & 0.16 & cloudy & safe \\
16 & 24.00 & 0.38 & 23.9 & 98.8 & 0.07 & cloudy & safe \\
\hline
\end{tabular}




\section{Conclusion}

The result of the tests shows that anemometer sensor and DHT22 are able to give accurate information on windspeed, air temperature, and humidity. The tests also give an acceptable error level or both anenometer sensor and DHT22. The error of anemometer is $2,7 \%$, and DHT22 error for temperature and humidity measurement are $1,42 \%$ and $1,1 \%$ respectively. Using neural network, the wave height can be forecasted by windspeed. The system shows that a "beware" warning category issued at windspeed of $14,91 \mathrm{~m} / \mathrm{s}$ and wave height of $1,72 \mathrm{~m}$, on cloudy weather at 12 a.m.

\section{ACKNOWLEDGMENTS}

We acknowlege the "Directorate General of Research and Community Development, Indonesia" which provides research fund. We also acknowledge our almamater, Jember University, for every support given.

\section{REFERENCES}

1. C. Cecioni, A. Abdolali, G. Bellota, and P. Sammarco. "Large-scale numerical modeling of hydro-acoustic waves generated by tsunamigenic earthquakes", Natural Hazards and Earth System Sciences Discussions Vol. 2, no. 7, pp. 4629-4658, 2014.

2. D. Parker. "Criteria for Evaluating the Condition of a Tropical Cyclone Warning System", Disasters, Vol. 23, No. 3, pp. 193-216, 1999.

3. H. Davies and M. Walters, "Do all crises have to become disasters? Risk and risk mitigation", Property Management, Vol. 16 issue 1, pp. 5-9, 1998.

4. J.S. Bridle, "Probabilistic Interpretation of Feedforward Classification Network Outputs, with Relationships to Statistical Pattern Recognition," NeurocomputingAlgorithms, Architectures and Applications, F. Fogelman-Soulie and J. Herault, eds., NATO ASI Series F68, Berlin: Springer-Verlag, pp. 227-236, 1989. (Book style with paper title and editor)

5. W.-K. Chen, Linear Networks and Systems. Belmont, Calif.: Wadsworth, pp. 123-135, 1993. (Book style)

6. H. Poor, "A Hypertext History of Multiuser Dimensions," MUD History, http://www.ccs.neu.edu/home/pb/mud-history.html. 1986. (URL link *include year)

7. K. Elissa, "An Overview of Decision Theory," unpublished. (Unplublished manuscript)

8. R. Nicole, "The Last Word on Decision Theory," J. Computer Vision, submitted for publication. (Pending publication)

9. C. J. Kaufman, Rocky Mountain Research Laboratories, Boulder, Colo., personal communication, 1992. (Personal communication)

10. D.S. Coming and O.G. Staadt, "Velocity-Aligned Discrete Oriented Polytopes for Dynamic Collision Detection," IEEE Trans. Visualization and Computer Graphics, vol. 14, no. 1, pp. 1-12, Jan/Feb 2008, doi:10.1109/TVCG.2007.70405. (IEEE Transactions )

11. S.P. Bingulac, "On the Compatibility of Adaptive Controllers," Proc. Fourth Ann. Allerton Conf. Circuits and Systems Theory, pp. 8-16, 1994. (Conference proceedings)

12. H. Goto, Y. Hasegawa, and M. Tanaka, "Efficient Scheduling Focusing on the Duality of MPL Representation," Proc. IEEE Symp. Computational Intelligence in Scheduling (SCIS '07), pp. 57-64, Apr. 2007, doi:10.1109/SCIS.2007.367670. (Conference proceedings)

13. J. Williams, "Narrow-Band Analyzer," PhD dissertation, Dept. of Electrical Eng., Harvard Univ., Cambridge, Mass., 1993. (Thesis or dissertation)

14. E.E. Reber, R.L. Michell, and C.J. Carter, "Oxygen Absorption in the Earth's Atmosphere," Technical Report TR-0200 (420-46)-3, Aerospace Corp., Los Angeles, Calif., Nov. 1988. (Technical report with report number)

15. L. Hubert and P. Arabie, "Comparing Partitions," J. Classification, vol. 2, no. 4, pp. 193-218, Apr. 1985. (Journal or magazine citation) 
16. R.J. Vidmar, "On the Use of Atmospheric Plasmas as Electromagnetic Reflectors," IEEE Trans. Plasma Science, vol. 21, no. 3, pp. 876-880, available at http://www.halcyon.com/pub/journals/21ps03-vidmar, Aug. 1992. (URL for Transaction, journal, or magzine)

17. J.M.P. Martinez, R.B. Llavori, M.J.A. Cabo, and T.B. Pedersen, "Integrating Data Warehouses with Web Data: A Survey," IEEE Trans. Knowledge and Data Eng., preprint, 21 Dec. 2007, doi:10.1109/TKDE.2007.190746.(PrePrint) 